\title{
900 V Reverse-Blocking GaN-on-Si MOSHEMTs with a Hybrid Tri-anode Schottky Drain
}

\author{
Jun Ma, Minghua Zhu, and Elison Matioli, Member, IEEE
}

\begin{abstract}
In this work we present high-performance GaN-on-Si metal-oxide-semiconductor high electron mobility transistors (MOSHEMTs) with record reverse-blocking (RB) capability. By replacing the conventional ohmic drain with a hybrid tri-anode Schottky drain, a high reverse breakdown voltage $\left(V_{B}^{R}\right)$ of $-900 \mathrm{~V}$ was achieved (at $1 \mu \mathrm{A} / \mathrm{mm}$ with grounded substrate), along with a small reverse leakage current $\left(I_{R}\right)$ of $\sim 20 \mathrm{nA} / \mathrm{mm}$ at $-750 \mathrm{~V}$. The devices also presented a small turn-on voltage $\left(V_{O N}\right)$ of $0.58 \pm 0.02$ $\mathrm{V}$, a small increase in forward voltage $\left(\Delta V_{F}\right)$ of $\sim 0.8 \mathrm{~V}$, a high $\mathrm{ON} / \mathrm{OFF}$ ratio over $10^{10}$, and a high forward breakdown voltage $\left(V_{\mathrm{B}}^{\mathrm{F}}\right)$ of $800 \mathrm{~V}$ at $20 \mathrm{nA} / \mathrm{mm}$ with grounded substrate. These results demonstrate a new milestone for RB GaN transistors, and open enormous opportunities for integrated GaN power devices.
\end{abstract}

Index Terms-GaN, HEMT, reverse blocking, Schottky diode, tri-gate, tri-anode, breakdown, leakage current.

\section{INTRODUCTION}

$\mathrm{R}$ everse-blocking (RB) transistors are crucial for many topologies of power converters, such as cyclo-converters, matrix converters, current source and multi-level inverters, some resonant converters, and among many others [1], which are highly desirable for applications that require reverse protection or bi-directional transfer of power [2,3].

While GaN-on-Si HEMTs emerge as promising candidates for future power conversion, HEMTs with RB capabilities are still rare up to date. In the few studies on RB-HEMTs [1], [4][7], the reverse blocking was typically achieved by integrating a Schottky barrier diode (SBD) into the drain electrode [8]-[11], yet these devices presented small $V_{\mathrm{B}}^{\mathrm{R}}$ and large $I_{\mathrm{R}}$, mainly limited by the generally poor reverse-blocking property of GaN SBDs. T. Morita et al. reported bi-directional GaN switches with RB capabilities using two monolithic normally-off gate injection transistors [12], which despite the highly integrated architecture for bidirectional switching, presented a limited $V_{\mathrm{B}}^{\mathrm{R}}$ voltage and a relatively large $V_{\mathrm{ON}}$.

Recently we have shown that the poor reverse blocking in lateral $\mathrm{AlGaN} / \mathrm{GaN}$ SBDs could be addressed by pinning the reverse voltage drop at the Schottky junction $\left(V_{\mathrm{SCH}}\right)$ at small levels [13]. This was demonstrated with a hybrid of tri-gate and tri-anode architectures, which allows a precise control over the pinch-off voltage $\left(V_{\mathrm{p}}\right)$ of the tri-gate/tri-anode regions to engineer the $V_{\mathrm{SCH}}$, resulting in $\mathrm{GaN}-$ on-Si SBDs with

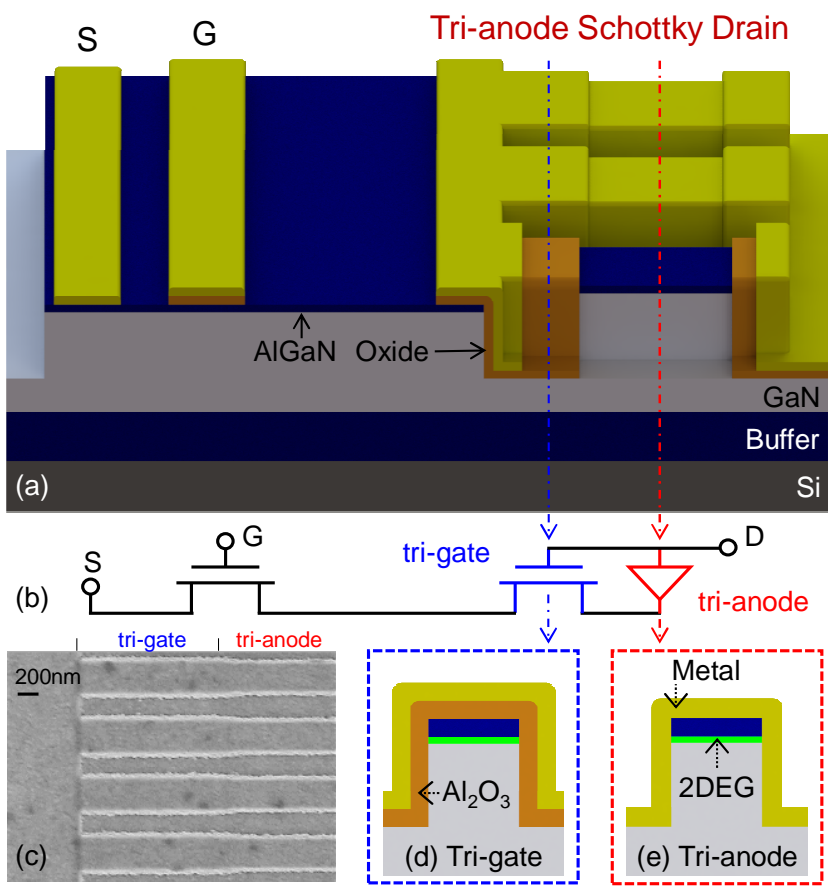

Fig. 1. (a) Schematic and (b) equivalent circuit of the reverse-blocking MOSHEMT. (c) Top-view SEM image of the hybrid tri-anode Schottky drain. (c) Cross-sectional schematics of (d) the tri-gate and (e) tri-anode regions.

simultaneously small $V_{\mathrm{ON}}$, low $I_{\mathrm{R}}$ and high $V_{\mathrm{B}}^{\mathrm{R}}[14]$. These results paved the path for the development of high-performance $\mathrm{RB}$ GaN transistors.

In this work, we demonstrate GaN-on-Si RB-MOSHEMTs with state-of-the-art reverse and forward performances, by replacing the conventional ohmic drain electrode with hybrid tri-anode SBDs. The devices presented a small $V_{\mathrm{ON}}$ of $0.58 \pm$ $0.02 \mathrm{~V}$, a small $\Delta V_{\mathrm{F}}$ of $0.8 \mathrm{~V}$, a high $V_{\mathrm{B}}^{\mathrm{R}}$ of $-900 \mathrm{~V}$ and $V_{\mathrm{B}}^{\mathrm{F}}$ of $800 \mathrm{~V}$, both with grounded substrate, along with a small $I_{\mathrm{R}}$ of $\sim 20 \mathrm{nA} / \mathrm{mm}$ at $-750 \mathrm{~V}$. These results are comparable to stateof-the-art discrete devices measured with grounded substrates, but achieved in a single integrated device, which reveal the extraordinary potential of the tri-anode Schottky drain to enable RB-MOSHEMTs as uni-directional power switches.

The authors are with the Power and Wide-band-gap Electronics Research Laboratory (POWERlab), École polytechnique fédérale de Lausanne (EPFL), CH-1015 Lausanne, Switzerland. (e-mail: jun.ma@epfl.ch; elison.matioli@epfl.ch). 

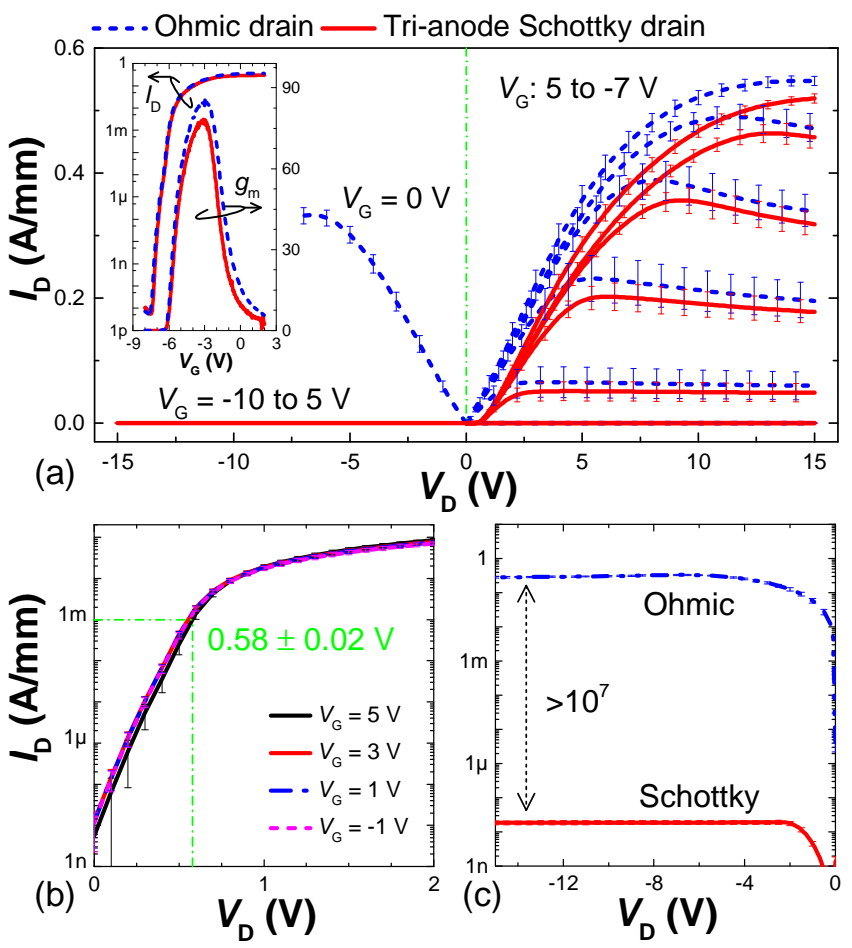

Fig. 2. (a) Output, (b) turn-ON and (c) reverse-blocking characteristics of the RB-MOSHEMTs and MOSHEMTs, normalized by the width of the device footprint. The inset shows the average transfer characteristics of the MOSHEMTs and RBMOSHEMTs, which were measured at $V_{\mathrm{D}}$ of $5 \mathrm{~V}$ and 5.6 $\mathrm{V}$, respectively.

\section{DEVICE DESIGN AND FABRICATION}

Figures 1(a) - (c) show the schematics, equivalent circuit and scanning electron microscopy (SEM) image of the RBMOSHEMT. The device consists of an ohmic electrode as the source, a MOS structure as the gate and a hybrid tri-anode Schottky diode as the drain. The latter integrates a tri-anode, trigate MOS and planar field plate (FP) regions. The sidewall metal in the tri-anode region (Fig. 1(e)) forms a direct Schottky contact to the 2DEG and leads to a small $V_{\mathrm{ON}}[15,16]$. In OFFstate, $V_{\mathrm{SCH}}$ is pinned at the $\left|V_{\mathrm{p}}\right|$ of the tri-anode region, which can be very small due to the elastic relaxation of the AlGaN/GaN nanowires [17], [18] and additional electrostatic control from the sidewall metals [19]-[28], resulting in a small $I_{\mathrm{R}}$ [13]-[14]. The tri-gate region (Fig. 1(d)) works as tri-gated FPs to shield the tri-anode region from high voltages, which along with the planar FP improves the $V_{\mathrm{B}}^{\mathrm{R}}$ [14], [29], [30].

The $\mathrm{AlGaN} / \mathrm{GaN}$ heterostructure in this work consisted of 2 $\mathrm{nm}$ of $\mathrm{GaN}$ cap, $24 \mathrm{~nm}$ of $\mathrm{Al}_{0.25} \mathrm{Ga}_{0.75} \mathrm{~N}$ barrier, $300 \mathrm{~nm}$ of undoped GaN channel and $5 \mu \mathrm{m}$ of buffer layers. The concentration and mobility of the 2DEG were about $1 \times 10^{13}$ $\mathrm{cm}^{-2}$ and $2000 \mathrm{~cm}^{2} / \mathrm{V} \cdot \mathrm{s}$, respectively. The device fabrication started with e-beam lithography to define the nanowires, which were etched by inductively coupled plasma with a depth of $\sim 180 \mathrm{~nm}$. The nanowire width $(w)$ and spacing (s) were both $300 \mathrm{~nm}$, corresponding to a filling factor $(F F=w /(w+s))$ of 0.5 . The device isolation was done by mesa etching, followed by the formation of the source ohmic contact. The ohmic

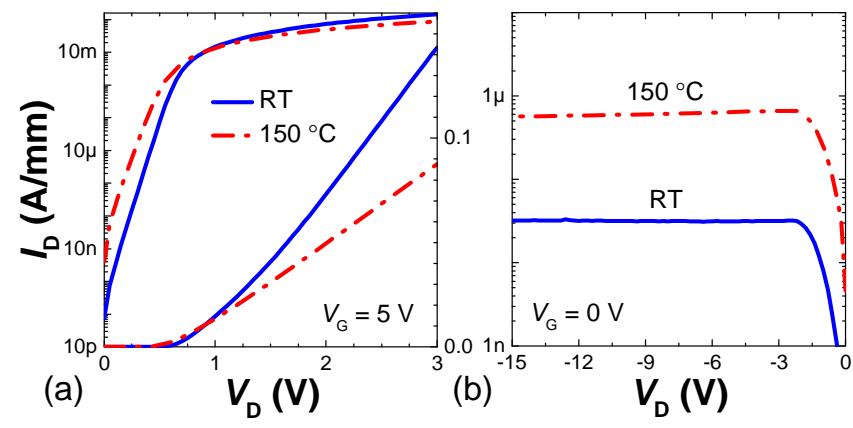

Fig. 3. (a) Forward and (b) reverse characteristics of the RB-MOSHEMTs at RT and $150^{\circ} \mathrm{C}$.

contact was formed by Ti/Al/Ti/Ni/Au (20/120/40/60/50 nm), annealed at $830{ }^{\circ} \mathrm{C}$ under forming gas for $30 \mathrm{sec}$. Then $10 \mathrm{~nm}$ $\mathrm{SiO}_{2}$ and $10 \mathrm{~nm} \mathrm{Al}_{2} \mathrm{O}_{3}$ were deposited by atomic layer deposition and selectively removed in the tri-anode region. The gate and drain contacts were formed using $\mathrm{Ni} / \mathrm{Au}$. The oxides in access/ohmic regions were later removed by wet etching, so the devices were not passivated, which however did not affect the leakage currents according to our observation. MOSHEMTs with the same dimensions but conventional ohmic drain electrodes were fabricated on the same chip as the reference.

All devices in this work had the same gate-to-source distance $\left(L_{\mathrm{SG}}\right)$, gate length $\left(L_{\mathrm{G}}\right)$, gate-to-drain distance $\left(L_{\mathrm{GD}}\right)$ of $1.5 \mu \mathrm{m}$, $2.5 \mu \mathrm{m}$ and $12.5 \mu \mathrm{m}$, respectively. The $L_{\mathrm{GD}}$ here refers to the distance between the gate and the tri-anode region. The lengths of the planar FP $\left(L_{\mathrm{FP}}\right)$ and tri-gate $\left(L_{\mathrm{TG}}\right)$ regions were $1.3 \mu \mathrm{m}$ and $1.2 \mu \mathrm{m}$, respectively. All device characteristics, such as drain current $\left(I_{\mathrm{D}}\right), I_{\mathrm{R}}$ and OFF-state forward leakage current $\left(I_{\mathrm{OFF}}\right)$, were normalized by the width of the device footprint, which was $60 \mu \mathrm{m}$, and their error bars were determined from measurements on 10 separate devices of the same kind.

\section{RESULTS AND DISCUSSION}

Figure 2(a) shows the forward output characteristics of the devices as well as their $I_{\mathrm{R}}$, revealing excellent performance of the RB-MOSHEMTs as uni-directional transistors. The differential $R_{\mathrm{ON}}$ and maximum $I_{\mathrm{D}}$ of the RB-MOSHEMTs were $13.8 \pm 0.6 \Omega \cdot \mathrm{mm}$ and $519 \pm 7 \mathrm{~mA} / \mathrm{mm}$, very close to those of the reference $(12.6 \pm 0.9 \Omega \cdot \mathrm{mm}$ and $547 \pm 7 \mathrm{~mA} / \mathrm{mm})$. The slight reduction in forward conductance can be possibly resolved by increasing the $F F$ in the hybrid tri-anode Schottky drain [9], [10]. The $V_{\mathrm{ON}}$ in the RB-MOSHEMTs was $0.58 \pm$ $0.02 \mathrm{~V}$ (Fig. 1(b)), extracted at $I_{\mathrm{D}}=1 \mathrm{~mA} / \mathrm{mm}$. The forward voltage at $I_{\mathrm{D}}=150 \mathrm{~mA} / \mathrm{mm}$ was increased from $2.13 \pm 0.16 \mathrm{~V}$ in the reference to $2.90 \pm 0.14 \mathrm{~V}$ in the RB-MOHSMETs, corresponding to a small $\Delta V_{\mathrm{F}}$ of about $0.8 \mathrm{~V}$. At $V_{\mathrm{D}}=-15 \mathrm{~V}$, the reference presented a large $I_{\mathrm{R}}$ of $280 \pm 10 \mathrm{~mA} / \mathrm{mm}$, while the $I_{\mathrm{R}}$ in the RB-MOSHEMTs was reduced by over 7 orders of magnitude to $19 \pm 2.4 \mathrm{nA} / \mathrm{mm}$ (Fig. 1(c)), which was also independent on the gate voltage $\left(V_{\mathrm{G}}\right)$ for a large range from -10 $\mathrm{V}$ to $5 \mathrm{~V}$. The inset in of Fig. 2(a) presents the average transfer characteristics of the MOSHEMTs and RB-MOSHEMTs. The devices presented a similar threshold voltage of $-6.6 \mathrm{~V}$, determined at $I_{\mathrm{D}}=1 \mu \mathrm{A} / \mathrm{mm}$, and a similar subthreshold slope $(S S)$ of $100 \pm 7 \mathrm{mV} / \mathrm{dec}$, along with a high ON/OFF ratio over $10^{10}$. The density of traps at the oxide/semiconductor interface 


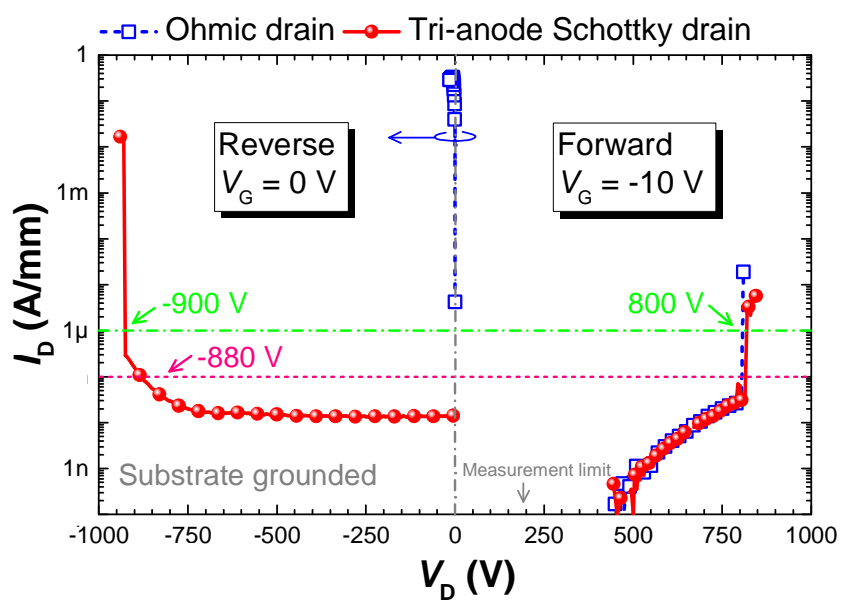

Fig. 4. Breakdown characteristics of the RB-MOSHEMTs and MOSHEMTs measured at room temperature with grounded substrate.

Table 1. Comparison of the RB-MOSHEMTs in this work with other reverseblocking GaN transistors in the literature. (*Substrate connection not reported.)

\begin{tabular}{|c|c|c|c|c|c|}
\hline & Substrate & $V_{\mathrm{RB}}$ & $I_{\mathrm{R}}(\mu \mathrm{A} / \mathrm{mm})$ & $V_{\mathrm{ON}}(\mathrm{V})$ & $\Delta V_{\mathrm{F}}(\mathrm{V})$ \\
\hline $\begin{array}{l}\text { This } \\
\text { work }\end{array}$ & $\mathrm{Si}$ & $\begin{array}{l}-900 \mathrm{~V} \text { at } 1 \mu \mathrm{A} / \mathrm{mm} \\
\text { (grounded sub.) }\end{array}$ & $\begin{array}{l}0.02 \text { at }-750 \mathrm{~V} \\
\text { (grounded sub.) }\end{array}$ & $\begin{array}{c}0.58 \pm \\
0.02\end{array}$ & 0.8 \\
\hline$[2]$ & $\mathrm{Si}$ & $\begin{array}{l}-321 \mathrm{~V} \text { at } 1 \mathrm{~mA} / \mathrm{mm} \\
\text { (floating sub.) } \\
-200 \mathrm{~V} \text { at } 1 \mathrm{~mA} / \mathrm{mm} \\
\text { (grounded sub.) }\end{array}$ & $\begin{array}{l}\geq 10 \text { at }-75 \mathrm{~V} \\
\text { (floating sub.) }\end{array}$ & 0.55 & 1.25 \\
\hline [4] & $\mathrm{SiC}$ & $-110 \mathrm{~V}$ at $10 \mathrm{~mA} / \mathrm{mm}$ & $\geq 1000$ at $-20 \mathrm{~V}$ & -- & -- \\
\hline$[5]$ & $\mathrm{Si}$ & $\begin{array}{l}-685 \mathrm{~V} \text { at hard } \\
\text { breakdown* }\end{array}$ & $\sim 6$ at $-100 \mathrm{~V}^{*}$ & 0.4 & -- \\
\hline$[6]$ & $\mathrm{Al}_{2} \mathrm{O}_{3}$ & $-49 \mathrm{~V}$ at $1 \mathrm{~mA} / \mathrm{mm}$ & $>100$ at $-25 \mathrm{~V}$ & 1.7 & $\geq 2$ \\
\hline [7] & $\mathrm{Si}$ & -- & $\begin{array}{l}\sim 0.4 \text { at }-20 \mathrm{~V} \\
\text { (floating sub.) }\end{array}$ & 1.91 & -- \\
\hline [12] & $\mathrm{Si}$ & $\begin{array}{l}-650 \mathrm{~V} \text { at } \sim 0.15 \\
\mathrm{~mA} / \mathrm{mm}^{*}\end{array}$ & -- & 1.5 & -- \\
\hline
\end{tabular}

of these devices was estimated from the $S S$, according to Ref. [31], which was $\sim 1.24 \times 10^{12} \mathrm{~cm}^{-2} \cdot \mathrm{eV}^{-1}$.

High temperature characteristics of the device are shown in Figure 3 . At $150^{\circ} \mathrm{C}$, the $V_{\mathrm{ON}}$ was reduced to $0.53 \mathrm{~V}$ and the $R_{\mathrm{ON}}$ was increased to $26.4 \Omega \cdot \mathrm{mm}$. The $I_{\mathrm{R}}$ was increased by a little over one order of magnitude, from $0.03 \mu \mathrm{A} / \mathrm{mm}$ to $0.57 \mu \mathrm{A} / \mathrm{mm}$, which was however still below $1 \mu \mathrm{A} / \mathrm{mm}$, revealing the excellent potential of the RB-MOSHEMTs for hightemperature applications.

Figure 4 shows the forward and reverse breakdown characteristics of the devices, measured with grounded substrate at room temperature. Both devices presented high forward breakdown voltages $\left(V_{\mathrm{B}}^{\mathrm{F}}\right)$ of about $800 \mathrm{~V}$ at 0.02 $\mu \mathrm{A} / \mathrm{mm}$ under a gate voltage $\left(V_{\mathrm{G}}\right)$ of $-10 \mathrm{~V}$, along with a very small $I_{\mathrm{OFF}}$ of about $6 \mathrm{nA} / \mathrm{mm}$ at $650 \mathrm{~V}$. While the MOSHEMTs showed no reverse-blocking capability, the reverse breakdown voltage $\left(V_{\mathrm{B}}^{\mathrm{R}}\right)$ of the RB-MOSHEMTs was as high as $-900 \mathrm{~V}$, along with a small $I_{\mathrm{R}}$ of about $0.02 \mu \mathrm{A} / \mathrm{mm}$ up to $-750 \mathrm{~V}$.

The RB-MOSHEMTs in this work were compared with other $\mathrm{RB}$ GaN transistors on various substrates in the literature (Tab. 1 ), presenting the smallest $I_{\mathrm{R}}$, the highest $V_{\mathrm{B}}^{\mathrm{R}}$, the smallest $\Delta V_{\mathrm{F}}$ along with a small $V_{\mathrm{ON}}$. The RB-MOSHEMTs presented the

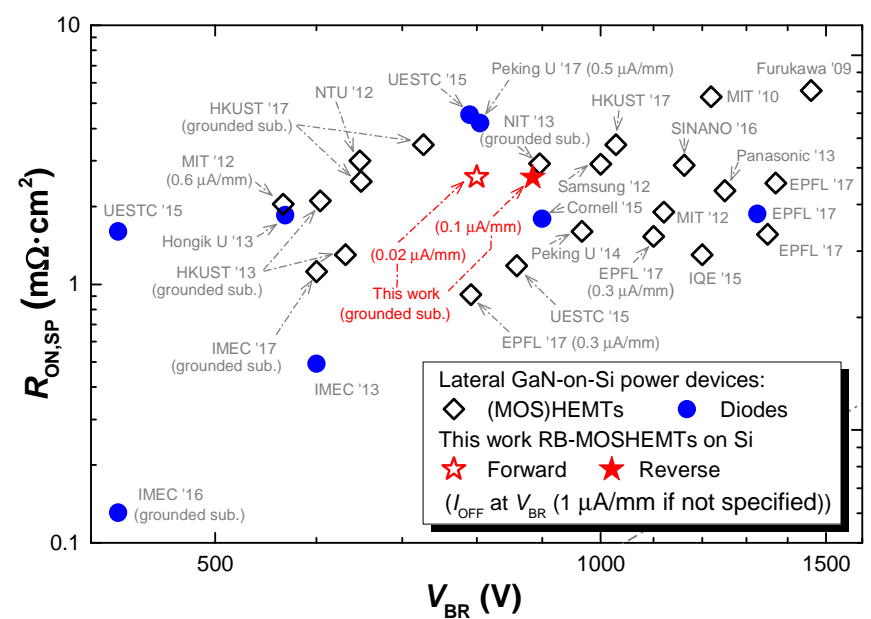

Fig. 5. Specific $R_{\mathrm{ON}}\left(R_{\mathrm{ON}, \mathrm{SP}}\right)$ versus breakdown voltage ( $\left.V_{\mathrm{BR}}\right)$ benchmarks the RB-MOSHEMTs against discrete GaN-on-silicon power (MOS)HEMTs and SBDs. The $V_{\mathrm{BR}}$ for all reference devices was re-calculated based on the reported data following the definition of $V_{\mathrm{BR}}$ at $I_{\mathrm{OFF}} \leq 1 \mu \mathrm{A} / \mathrm{mm}$. A total transfer length of $3 \mu \mathrm{m}$ was considered for the calculation of $R_{\mathrm{ON}, \mathrm{SP}}$, accounting for both source and drain contacts. For fair comparison, literature results with unspecified $R_{\mathrm{ON}}$ or $I_{\mathrm{R}}$ were not included.

smallest $I_{\mathrm{R}}$ because their $V_{\mathrm{SCH}}$ was pinned at a small bias of $\sim 2.3$ $\mathrm{V}$, determined by the pinch-off of the tri-anode region, regardless of the increase in reverse bias. This makes the $I_{\mathrm{R}}$ saturate at a small level instead of increasing exponentially with voltage [13]. The high $V_{\mathrm{B}}^{\mathrm{R}}$ obtained in this work is attributed to the better-distributed electric field under reverse biases. In the hybrid tri-anode drain, two field plates, e.g. the planar and the tri-gate regions, are integrated with the tri-anode, by simply engineering their pinch-off voltages with the tri-gate approach, which spread effectively the electric field and improved the $V_{\mathrm{B}}^{\mathrm{R}}$ $[29,30]$.

We benchmarked our devices against state-of-the-art discrete GaN-on-silicon power MOSHEMTs and SBDs in Fig. 5. The RB-MOSHEMTs in this work presented both high $V_{\mathrm{B}}^{\mathrm{F}}$ and $V_{\mathrm{B}}^{\mathrm{R}}$, comparable to state-of-the-art discrete devices measured with grounded substrates, revealing their extraordinary potential as uni-directional power transistors. More importantly, both the high $V_{\mathrm{B}}^{\mathrm{F}}$ and $V_{\mathrm{B}}^{\mathrm{R}}$ were achieved in a single integrated device in this work, instead of using a discrete transistor in series with an SBD, which can greatly simplify the circuit design, reducing its size, resistance and parasitic components, and improve the efficiency of power converters.

\section{CONCLUSION}

In this work we presented GaN-on-Si MOSHEMTs with excellent reverse-blocking capability based on a hybrid trianode Schottky drain. The devices exhibited a small $V_{\mathrm{ON}}$ of 0.58 $\pm 0.02 \mathrm{~V}$, a small $\Delta V_{\mathrm{F}}$ of $0.8 \mathrm{~V}$, a high ON/OFF ratio over $10^{10}$, a record high reverse breakdown voltage of $900 \mathrm{~V}$ (at $1 \mu \mathrm{A} / \mathrm{mm}$ with a grounded substrate), and a small $I_{\mathrm{R}}$ of about $20 \mathrm{nA} / \mathrm{mm}$ at $-750 \mathrm{~V}$, revealing the significant potential of these devices for future efficient and compact GaN power converters. 


\section{REFERENCES}

[1] A. Lindemann, "A new IGBT with reverse blocking capability." in Proc. the 9th European Conf. on Power Elec. and Appl.(EPE), Graz, Austria, 2001, pp. 27-29.

[2] C. Zhou, W. Chen, E. L. Piner and K. J. Chen, "Schottky-ohmic drain AlGaN/GaN normally off HEMT with reverse drain blocking capability," IEEE Electron Device Letters, vol. 31, no. 7, pp. 668-670, July 2010. doi: 10.1109/LED.2010.2048885.

[3] E. R. Motto, J. F. Donlon, M. Tabata, H. Takahashi, Y. Yu and G. Majumdar, "Ap plication characteristics of an experimental RB-IGBT (reverse blocking IGBT) module," Conference Record of the 2004 IEEE Industry Applications Conference, 2004. 39th IAS Annual Meeting., 2004, pp. 1540-1544 vol.3. doi: 10.1109/IAS.2004.1348675.

[4] E. Bahat-Treidel, R. Lossy, J. Wurfl and G. Trankle, "AlGaN/GaN HEMT with integrated recessed Sc hottky-drain protection diode," IEEE Electron Device Letters, vol. 30, no. 9, pp. 901-903, Sept. 2009. doi: 10.1109/LED.2009.2026437.

[5] J. -G. Lee, S. -W. Han, B. -R. Park, and H. -Y. Cha, "Unidirectional AlGaN/GaN-on-Si HFETs with reverse blocking drain," Applied Physcis Express, vol. 7, pp. 014101-1-014101-4, Dec. 2013. doi: 10.7567/APEX.7.014101.

[6] S. -L. Zhao, M. -H. Mi, B. Hou, J. Luo, Y. Wang, Y. Dai, J. -C. Zhang, X. -H. Ma, and H. Yue, "Mechanism of improving forward and reverse blocking voltages in AlGaN/GaN HEMTs by using Schottky drain," Chinese Physics B, vol. 23, pp. 107303-1-107303-5, Aug. 2014. doi: 10.1088/1674-1056/23/10/107303.

[7] A. Taube, J. Kaczmarski, R. Kruszka, J. Grochowski, K. Kosiel, J. Gołaszewska-Malec, M. Sochacki, W. Jung, E. Kamińska, and A. Piotrowska, "Temperature-dependent electrical characterization of highvoltage AlGaN/GaN-on-Si HEMTs with Schottky and ohmic drain contacts," Solid-State Electronics, vol. 111, pp. 12-17, Apr. 2015. doi: 10.1016/j.sse.2015.04.001

[8] B. Lu, E. L. Piner and T. Palacios, "Schottky-drain technology for AlGaN/GaN high-electron mobility transistors," IEEE Electron Device Letters, vol. 31, pp. 302-304, Apr. 2010. doi: 10.1109/LED.2010.20407041.

[9] W. Mao, W. -B. She, C. Yang, J. -F. Jin, X. -F. Zheng, C. Wang, and Y. Hao, "Reverse blocking characteristics and mechanisms in Schottky-drain AlGaN/GaN HEMT with a drain field plate and floating field plates," Chinese Physics B, vol. 25, pp. 017303-1-017303-6, Dec. 2015. doi: 10.1088/1674-1056/25/1/017303.

[10] P. -G. Chen, M. Tang, M. -H. Liao, and M. H. Lee, "In0.18Al0.82n/AlN/GaN MIS-HEMT on $\mathrm{Si}$ with Schottky-drain contact," Solid-State Electronics, vol. 129, pp. 206-209, Nov. 2016. doi 10.1016/j.sse.2016.11.002

[11] Y. W. Lian, Y. S. Lin, H. C. Lu, Y. C. Huang and S. S. H. Hsu "AlGaN/GaN HEMTs on silicon with hybrid schottky-ohmic drain for high breakdown voltage and low leakage current," IEEE Electron Device Letters, vol. 33, pp. 973-975, Jul. 2012. doi: 10.1109/LED.2012.2197171.

[12] T. Morita, M. Yanagihara, H. Ishida, M. Hikita, K. Kaibara, H. Matsuo, Y. Uemoto, T. Ueda, T. Tanaka, and D. Ueda, " $650 \mathrm{~V} 3.1 \mathrm{~m} \Omega \cdot \mathrm{cm}^{2} \mathrm{GaN}$ based monolithic bidirectional switch using normally-off gate injection transistor," 2007 IEEE International Electron Devices Meeting, Washington (IEDM), DC, 2007, pp. 865-868. doi 10.1109/IEDM.2007.4419086.

[13] J. Ma, D. C. Zanuz, E. Matioli, "Field plate design for low leakage current in lateral GaN power Schottky diodes: role of the pinch-off voltage," IEEE Electron Device Letters, vol. 38, pp. 1298-1301, Sept. 2017. doi 10.1109/LED.2017.2734644

[14] J. Ma and E. Matioli, "High-voltage and low-leakage AlGaN/GaN trianode Schottky diodes with integrated tri-gate transistors," IEEE Electron Device Letters, vol. 38, no. 1, pp. 83-86, Jan. 2017. doi 10.1109/LED.2016.2632044.

[15] E. Matioli, B. Lu and T. Palacios, "Ultralow Leakage Current AlGaN/GaN Schottky Diodes With 3-D Anode Structure," IEEE Transactions on Electron Devices, vol. 60, no. 10, pp. 3365-3370, Oct. 2013. doi: 10.1109/TED.2013.2279120.

[16] J. Ma, G. Santoruvo, P. Tandon and E. Matioli, "Enhanced electrical performance and heat dissipation in AlGaN/GaN Schottky barrier diodes using hybrid tri-anode structure," IEEE Transactions on Electron Devices, vol. 63, no. 9, pp. 3614-3619, Sept. 2016. doi: 10.1109/TED.2016.2587801.
[17] M. Azize, and T. Palacios, "Top-down fabrication of AlGaN/GaN nanoribbons," Applied Physics Letters, vol. 98, pp. 042103-1-042103-3, Jan. 2011. doi: 10.1063/1.3544048.

[18] S. Liu, Y. Cai, G. Gu, J. Wang, C. Zeng, W. Shi, Z. Feng, H. Qin, Z. Cheng, K. J. Chen, and B. Zhang, "Enhancement-mode operation of nanochannel array (NCA) AlGaN/GaN HEMTs," IEEE Electron Device Letters, vol. 33, pp. 354-356, Mar. 2012. doi: 10.1109/LED.2011.2179003.

[19] D. S. Lee, H. Wang, A. Hsu, M. Azize, O. Laboutin, Y. Cao, J. W. Johnson, E. Beam, A. Ketterson, M. K. Schuette, P. Saunier, and T. Palacios, "Nanowire channel InAIN/GaN HEMTs with high linearity of $g_{\mathrm{m}}$ and $f_{\mathrm{T}}$," IEEE Electron Device Letters, vol. 34, pp. 969-971, Aug. 2013. doi: 10.1109/LED.2013.2261913.

[20] D. F. Brown, Y. Tang, D. Regan, J. Wong and M. Micovic, "Self-Aligned AlGaN/GaN FinFETs," IEEE Electron Device Letters, in press, 2017. doi: 10.1109/LED.2017.2747843.

[21] Y. He, M. Mi, C. Wang, X. Zheng, M. Zhang, H. Zhang, J. Wu, L. Yang, P. Zhang, X. M, and Y. Hao, "Enhancement-mode AlGaN/GaN nanowire channel high electron mobility transistor with fluorine plasma treatment by ICP," IEEE Electron Device Letters, in press, 2017. doi: 10.1109/LED.2017.2736780.

[22] H. Zhou, X. Lou, S. B. Kim, K. D. Chabak, R. G. Gordon and P. D. Ye, "Enhancement-mode AlGaN/GaN Fin-MOSHEMTs on Si substrate with atomic layer epitaxy $\mathrm{MgCaO}$," IEEE Electron Device Letters, vol. 38, pp. 1294-1297, Sept. 2017. doi: 10.1109/LED.2017.2731993.

[23] S. Arulkumaran, G. I. Ng, C. M. Manojkumar, K. Ranjan, K. L. Teo, O. F. Shoron, S. Rajan, S. B. Dolmanan, and S. Tripathy, "In ${ }_{0.17} \mathrm{Al}_{0.83} \mathrm{~N} / \mathrm{AlN} / \mathrm{GaN}$ triple t-shape Fin-HEMTs with $g_{\mathrm{m}}=646 \mathrm{mS} / \mathrm{mm}$, $I_{\mathrm{ON}}=1.03 \mathrm{~A} / \mathrm{mm}, I_{\mathrm{OFF}}=1.13 \mu \mathrm{A} / \mathrm{mm}, S S=82 \mathrm{mV} / \mathrm{dec}$ and DIBL$=28 \mathrm{mV} / \mathrm{V}$ at $\mathrm{VD}=0.5 \mathrm{~V}, " 2014$ IEEE International Electron Devices Meeting (IEDM), San Francisco, CA, 2014, pp. 25.6.1-25.6.4. doi: 10.1109/IEDM.2014.7047109.

[24] S. Arulkumaran, G. I. Ng, C. M. Manojkumar, K. Ranjan, K. L. Teo, O. F. Shoron, S. Rajan, S. B. Dolmanan, and S. Tripathy, "Electron velocity of $6 \times 10^{7} \mathrm{~cm} / \mathrm{s}$ at $300 \mathrm{~K}$ in stress engineered InAlN/GaN nano-channel high-electron-mobility transistors," Applied Physics Letters, vol. 160, pp. 053502-1-053502-5, Feb. 2015. doi: 10.1063/1.4906970.

[25] K. S. Im, C. -H. Won, Y. -W. Jo, J. -H. Lee, M. Bawedin, S. Cristoloveanu, and J. -H. Lee, "High-performance GaN-based nanochannel FinFETs with/without AlGaN/GaN heterostructure," IEEE Transactions on Electron Devices, vol. 60, pp. 3012-3018, Oct. 2013. doi: 10.1109/TED.2013.2274660.

[26] K. Zhang, Y. Kong, G. Zhu, J. Zhou, X. Yu, C. Kong, Z. Li, and T. Chen, "High-linearity AlGaN/GaN FinFETs for microwave power applications," IEEE Electron Device Letters, vol. 38, pp. 615-618, May 2017. doi: 10.1109/LED.2017.2687440.

[27] K. -S. Im, H. -S. Kang, J. -H. Lee, S. -J. Chang, S. Cristoloveanu, M. Bawedin, J. -H. Lee, "Characteristics of GaN and AlGaN/GaN FinFETs," Solid-State Electronics, vol. 97, pp. 66-75, Jul. 2017. doi: 10.1016/j.sse.2014.04.033.

[28] K. -S. Im, H. -S. Kang, D. -K. Kim, S. Vodapally, Y. H. Park, J. -H. Lee, Y. -T. Kim, S. Cristoloveanu, and J. -H. Lee, "Temperature-dependent characteristics of AlGaN/GaN FinFETs with sidewall MOS channel," Solid-State Electronics, vol. 120, pp. 47-51, Jun. 2016. doi: doi.org/10.1016/j.sse.2016.03.007.

[29] J. Ma and E. Matioli, "High performance tri-gate GaN power MOSHEMTs on silicon substrate," IEEE Electron Device Letters, vol. 38, no. 3, pp. 367-370, March 2017. doi: 10.1109/LED.2017.2661755.

[30] J. Ma and E. Matioli, "Slanted tri-gates for high-voltage GaN power devices," IEEE Electron Device Lett., vol. 38, pp. 1305-1308, Sept. 2017. doi: 10.1109/LED.2017.2731799.

[31] B. Lu, E. Matioli and T. Palacios, "Tri-gate normally-off GaN power MISFET," IEEE Electron Device Letters, vol. 33, no. 3, pp. 360-362, Mar. 2012. doi: 10.1109/LED.2011.2179971.

(C) 2017 IEEE. Personal use of this material is permitted. Permission from IEEE must be obtained for all other uses, in any current or future media, including reprinting/republishing this material for advertising or promotional purposes, creating new collective works, for resale or redistribution to servers or lists, or reuse of any copyrighted component of this work in other works. 